\title{
Effects of Auditory Simulation and Personality Types on Working Memory
}

\author{
Nancy David ${ }^{1 *}$, Kimberley Muzeyi ${ }^{2}$, Sonia Elizabeth Prasadam ${ }^{3}$
}

\section{ABSTRACT}

Working memory is very crucial as it influences higher cognition. We conducted a study testing auditory simulations effect on working memory while considering personality type. 161 participants college students did the Eysenck personality questionnaire (EPQ-R) as a pretest, followed by reading a prose with an auditory simulation based assigned group (pop, classical, white noise and silence). Then they answered multiple-choice questions based on the prose in silence. We found that pop and classical groups did better, although the difference across groups was not significant. Hence auditory simulations have no negative or significant positive effects on working memory, furthermore, unlike previous studies, personality didn't affect performance. Future studies can consider participants' preferences and context-dependent memory to better explore this phenomenon.

Keywords: Prose Retention, Working Memory, Auditory Simulations, Extraversion And Introversion, Music, White Noise

$\mathrm{M}$ emory is the means by which we draw on our past experiences in order to use this information in the present (Sternberg, 1999). Memory plays a crucial role in all our lives, without the awareness, information and memory of our past events, it can be extremely hard to function in the present or plan the future. This is because we use the stored information and experiences to make sense of our surroundings and adapt efficiently. According to Atkinson and Shiffrin (1968), there are three stores of memory: the sensory register, which helps us perceive and make sense of our surroundings, has the smallest retention span, short-term memory (STM) and long-term memory (LTM), helps store the relatively permanent information (Malmberg \& Shiffrin). The information is passed from the sensory register and STM which then based on factors like importance, rehearsals and other factors get consolidated in the LTM. Elaborating on STM, Baddeley and Hitch (1974) proposed the model of "working memory" which they suggested retains and uses the information previously stored or presently experienced for our daily function. Although the model of working memory has evolved and its relation with STM is blurred through

${ }^{1}$ BA, final year,Department of Music, CHRIST (Deemed to be University), Bangalore, Karnataka, India.

${ }^{2}$ BA, final year, Department of Music, CHRIST (Deemed to be University), Bangalore, Karnataka, India.

${ }^{3}$ Assistant Professor, Department of Psychology, CHRIST (Deemed to be University), Bangalore, Karnataka, India.

*Corresponding Author

Received: January 16, 2021; Revision Received: March 21, 2021; Accepted: March 31, 2021

(C) 2021, David N., Muzeyi K. \& Prasadam S.E.; licensee IJIP. This is an Open Access Research distributed under the terms of the Creative Commons Attribution License (www.creativecommons.org/licenses/by/2.0), which permits unrestricted use, distribution, and reproduction in any Medium, provided the original work is properly cited. 
rigorous study in the field, working memory has been observed to be an independent mechanism, which links and uses information and functions from different cognitive mechanisms. It is believed that it facilitates various important cognitive functions such as learning, attention, intelligence and language (Chai, Hamid \& Abdulla, 2018), the evidence of this has grown from theoretical implications to everyday practicality.

\section{Working Memory and its Relationship with other Cognitive and Mental Processes}

For instance, intelligence, which can be defined as "the aggregate or global capacity of the individual to act purposefully, to think rationally and to deal effectively with his environment" (Wechsler, 1944). Giofrè \& Cornoldi (2014) states that working memory greatly influences an individual's intelligence to the extent that one's working memory capacity must be tested to determine one's true intellectual capability. Intelligence cannot be isolated from the concept of learning because of their interdependency (Jenson, 1989). Learning is a "relatively permanent change in the behavior that results from reinforced practice or experience" (Steers and Porter, 2010). Memory aids learning by enabling the individual to recall these practices and experiences.

As working memory helps the individual to understand and make sense of the material being learned there has been a strong correlation made between learning disabilities and academic underachievement with poor working memory functions (Holmes, Gathercole and Dunning, 2010) as well as stable and functional working memory with excellent academic learning and intelligence (Dehn, 2008). For learning to occur one must be able to focus on the task at hand or the material to be learned, which links the process to attention. According to Sarter \& Lustig (2009), the relationship and link between attention, learning and memory can be drawn through various conceptual models and neurological theories of the processes. The cognitive processes of attention and working memory work hand in hand for executing our day-to-day tasks, attention provides the selective focus and working memory makes information accessible to execute various tasks, which is crucial for cognitive functions (Fougnie, 2008), (Long, Kuhl \& Chun, 2018). Apart from the mentioned cognitive functions working memory also plays a significant role in various other cognitive processes such as higher reasoning, problem-solving, decision making (Morrison, 2005; Chai, Hamid \& Abdulla, 2018; Jarrold \& Towse 2006). While people of all age groups use these processes, one group that highly depends on this on a daily basis are college students.

\section{Working Memory and College Students}

Being able to remember and apply learned concepts is crucial for any college student and working memory plays an important role in all of the complex cognitive functions that make doing those tasks possible. Stress and anxiety are major factors that hinder academic performance in students. This is because not only does it have a negative effect on the emotional well-being of the students but also it dampens crucial cognitive processes like attention, thinking and also working memory (Sänger et al, 2014; Porcelli et al, 2008; Lukasik et al, 2019). Hence, stress management highly influences academic success. One method to manage stress and anxiety is muscle relaxation, which fares well among college students and boosts their academic performance (Hubbard \& Blyler 2016). This form of relaxation can be attained by engaging in various activities such as mindful meditation and listening to calming music. During concentration tasks, one's auditory senses are heightened, thus the auditory simulations can affect one's performance. 


\section{Auditory Simulations and Working Memory}

The relaxation achieved by various auditory simulations is tested and proven helpful (Molina, Sainz, Serrano, Rentería \& Urquiza, 2014). Auditory simulations are also helpful because of its effect on the brain as a pleasant auditory stimulus (musically consonant) promotes function in the sensory and frontal cortex (Griffin, 2006). Over a long period, researchers have tested the effect of auditory simulations on working memory and related mechanisms, which reaped mixed results in different places and on different populations. Some prevalent auditory simulations used in these experiments include popular music, western classical music and white noise. Many experiments among these were conducted on short-term memory, working memory and learning, hence a few ideas can be drawn from the findings of these papers. With popular music most researchers expected the results to be a negative association considering that the lyrics may confuse or affect attention negatively, some works like Musliu, Berisha, Musaj, Latifi \& Peci (2017) confirmed with it, while others like Dodge \& Mensink (2014), Langan \& Sachs (2013), Bird (2017) and Tiu (2013) found contradicting discoveries that it influenced memory positively. Classical music has largely seen positive association and various research supported this association with their findings (Lehmann \& Seufert, 2017; Sachs \& Carden 2012; Hetland, 2000; Taylor \& Rowe 2012), however, a few other researchers found their analysis pointing at a negative effect of classical music on working memory (Dodge \& Mensink, 2014). White noise or simulated decibels have found equal acceptance as an aid as classical music that was backed by several experiments (Söderlund, Sikström, Loftesnes \& Sonuga-Barke, 2010) though like classical music, white noise was found distracting by a few (Deigård 2012). Another potential influencing factor suggested was personality in this phenomenon.

\section{Personality and Working Memory}

American Psychological Association (APA) defines personality as "Individual differences in characteristic patterns of feeling, thinking and behaving". Since it is a pattern of one's thinking along with its other aspects it could be an influencing factor for not only emotional well-being but also cognitive functions of the person. Many studies conducted to test the relationship between various cognitive functions like intelligence, attention, memory and personality characteristics and types have found results suggesting a positive correlation between the two (Sutin, Stephan, Luchetti, \& Terracciano, 2019; Rammstedt, Lechner, \& Danner, 2018; Zeidner \& Matthews, 2000; Ackerman \& Heggestad, 1997). The Anterior Cingulated Cortex (ACC) a place in the brain that connects the limbic system (which controls emotional regulation) and the prefrontal cortex (which is related to cognitive functions) further adds to the relationship between personality and cognition which can be inferred through this (Stevens, Hurley, \& Taber, 2011). There has been evidence that working memory function and load modulates the ACC further influencing emotional and behavioral regulation (Gray \& Braver, 2002). Extraverts and introverts have been found to have different preferences when it comes to work and study environments where introverts prefer quiet places that aren't externally stimulating, extraverts prefer being surrounded with people and thrive at cognitive tasks when in externally stimulating conditions. Hence, while choosing auditory stimulus, moderation must be maintained as introverts were found to be at a disadvantage in the presence of an auditory stimulus, which causes overstimulation or arousal (Campbell \& Hawley, 1982)

\section{Appropriate Auditory Simulation for Potential Cognitive Aid}

The term auditory simulation in this context refers to different auditory stimuli which are manipulated, added or made absent to achieve a specific goal. These differences occur as a result of making changes to the main constituents of music; tempo, dynamics, pitch, melody, 
harmony and tonality (Hill, 2013; Griffin, 2006). It was found that the appropriate tempo should be within the range of 70-110 BPM, as it is closest to a human resting heart rate (Griffin 2006; Hill 2013; Strachan, 2015). Furthermore, research shows that loud and fast music had negative effects on cognitive performance (Thompson \& Schellenberg, 2011; Kathleen and Sachs, 2013), because an increase in tempo increases the pulse of a piece of music or said auditory simulation, and this leads to more physical arousal.

Tonality is determined by the scale, key or mode the piece uses, minor and major being the most known and used scales. Consonant Music is found to be more effective as it requires less mental processing (due to the familiar feeling it evokes); minimal changes in dynamics (the relative changes in the loudness and softness of music), repetition of melodic and rhythmic phrases and a high pitch range is found to have the same effect (Hill, 2013). Studies show that high frequencies, such as those found in white noise, produce positive results in student behavior, as it triggers the release of endorphins and had affected blood pressure positively (Söderlund \& Sikström, 2010; Deigård, 2012; Hill, 2013; Daud \& Sudirman, 2015). Another quality was the effectiveness of instrumental music as opposed to vocal music as vocal music causes overstimulation, a study conducted by Salami \& Baddeley in 1989 found that music with vocals or speech-related music had a negative impact on the performance on phonologically related memory tasks, since it may activate the speech processing area of the brain (Lehmann \& Seutfert, 2017; Musilu \& Barisha, 2017; Bird 2017). It was also found that listening to familiar music negatively affects the concentration of students and thus resulting in low-performance quality and disadvantageous for certain personality types (Bird, 2017; Tiu, 2013).

\section{Research Rationale}

This phenomenon has been gaining a lot of curiosity in the research community and has been reaping mixed results with different kinds of auditory simulations, this study tested some of the most used auditory simulations in past research and compared performance among them. The experiments conducted with this phenomenon has mostly been on adults $(30+)$, children and adolescents and rarely on the youth population, this study tested the phenomenon among emerging adults who are pursuing higher education (undergraduate and postgraduate students). Since the population is college students the aspect of prose retention in working memory would be tested as it is not often tested due to population constraints. This would also help observe any differences in performance compared to other populations, as college students increasingly indulge themselves in rigorous cognitive tasks by exploring new fields and trying to get a deeper understanding of the subjects they are majoring in. The factor of extraversion and introversion is accounted for in this study as it was suggested to be an influencing variable on performance in past literature due to the tendency in introverts to prefer working in silence. The inclination towards music and using it as an aid differs across cultures and as two of the auditory simulations in this study are musical, this study also gives an account for the effect and difference that influences performance due to cultural difference.

\section{Research Question}

This experimental study aims to address the following questions; firstly, do varying auditory simulations affect working memory performance? Secondly, do personality types influence performance quality in working memory tasks in this phenomenon? 
METHODOLOGY

This study followed a true experimental design. The independent and dependent variables were the auditory simulation and recall respectively. A confounding variable that identified was extraversion and introversion; they were tested so the effect of it would be noticed if any.

\section{Hypothesis}

$\mathrm{H}_{1}=$ There is a difference in recall between the different auditory environments tested.

$\mathrm{H}_{0}=$ There is no difference between performance quality between introverts and extraverts in working memory tasks in the presence and absence of auditory simulations.

\section{Sample}

The experiment was conducted on 161 college students studying in Bangalore, India who fell under the emerging adults' population (18-25 age groups). Participants were students of both sexes from the differing socioeconomic and educational backgrounds making the sample diverse and have equal representation. Convenience sampling method was used to identify participant population. People who may have any hearing impairments, sound sensitivity, any nature of mental illnesses or cognitive impairment were excluded from the experiment as this would put them at a disadvantage and affect the findings of the study. Students who did not have English as a first language in school were also excluded as the prose piece was in English and required efficient English comprehension.

\section{Tools}

Eysenck's personality questionnaire (EPQR; 1985) was used to test personality. The reliability variable is ranging from .85 to .90 for extraversion (Weaver \& Kiewitz, 2006), for this study we would only be using the extraversion aspect of this personality questionnaire. This tool will help determine the factor of extraversion and introversion which seems to be a contributing factor in many studies dealing with this topic (Furnham \& Strbac, 2002; McDonald, 2013; Gold et al., 2013; Nadler, 2010). For the prose retention task, 5 short prose passages taken from TOEFL sample questions (http://www.ets.org/toefl) consisting of different topics were selected and administered to a random sample of people who rated them on a scale of 1 to 5 ( 1 being very easy, 5 being extremely hard). The passage which was rated 'average' by most of the participants was picked for the experiment. The music selected for the experiments are; L.V Beethoven's Violin Concerto in D major, Op 61 for the classical simulation "Sunrise" by Bob Leon for the pop simulation, and white noise from an application (white noise.studio md). Each had a tempo within the range of 70-110 BPM and is instrumental. Both musical pieces were chosen because they fit within the genre but were not too well known to serve as a distraction for the participants. Each was played at a moderate volume within the range of $35-45 \mathrm{~dB}$.

\section{Procedure}

After acquiring permission from the research and ethics board, college students from across Bangalore, India were invited, the people who fit the exclusion and inclusion criteria were selected for the experiment. After clarifying queries and explaining the aims of the study and the experiment thoroughly, informed consent was taken from the participants. The Participants were first administered with the Eysenck's personality questionnaire as a pretest.

Before the experiment began the participants were randomly assigned into four groups; Pop music, Classical Music, White noise (experimental groups) and Silence (control group). At 
the beginning of the experiment, the participants were given a short prose piece. Then the participants were asked to read the text while the auditory simulation was played. At the end of the reading task, the auditory environment was changed to silence and then the participants were given a questionnaire based on the prose that they read, the questions were of two types, recognition and recall but in the format of a multiple-choice pattern. They were to answer the questions and return the questionnaire. All of the ethical guidelines set by the APA were followed throughout the process of this experiment.

Table 1 Design of the groups

\begin{tabular}{lllll} 
Different tasks & Condition 1 & Condition 2 & Condition 3 & Condition 4 \\
\hline reading task & White noise & Classical music & Pop & Silence \\
recall task & Silence & Silence & Silence & Silence \\
\hline
\end{tabular}

The table above illustrates the condition in which the reading and recall tasks were carried out.

\section{RESULTS}

The data (scores across different simulations and scores among introverts and extraverts with and without auditory simulation) was first tested for normality when both were not found to be normally distributed it was further analyzed by Kruskal-Wallis test for scores across groups and Mann-Whitney U Test for personality analysis.

Table 2 Descriptive statistics

\begin{tabular}{lllll}
\hline & N & Mean & SD & N \\
\hline Pop & 40 & 6.1250 & 1.76 & .960 \\
Classical & 40 & 6.4750 & 1.97 & .960 \\
White Noise & 41 & 5.6585 & 2.28 & $.918^{*}$ \\
Silence & 40 & 5.5750 & 1.74 & .948 \\
Extraverts (Silence) & 25 & 5.60 & 1.89 & $.965^{*}$ \\
Introverts (Silence) & 15 & 5.53 & 1.50 & $.867^{*}$ \\
Extraverts (Auditory Simulations) & 82 & 6.17 & 2.14 & .950 \\
Introverts (Auditory Simulations) & 39 & 5.90 & 1.75 & .944 \\
\hline
\end{tabular}

Table 1 indicates the mean, median and standard deviation of performance of each of the different auditory simulation groups and of extraverts and introverts who performed the task in silence and the presence of an auditory simulation. The Shapiro-Wilk test $(\mathrm{N})$ column indicates that the data is not normally distributed and hence a non-parametric test was used. 
Table 3 Inferential statistics

\begin{tabular}{llll}
\hline Groups & N & $\begin{array}{l}\text { Kruskal- } \\
\text { Wallis }\end{array}$ & $\begin{array}{l}\text { Significance } \\
\text { level }\end{array}$ \\
\hline Recall scores across all four auditory environment & 161 & 6.075 & .108 \\
\hline
\end{tabular}

As the data was not normally distributed Kruskal-Wallis non-parametric test was done. The table above reports that the difference between the recall performance across the different environments (.108) is more than .05 hence it isn't significant.

Table 4 Inferential statistics

\begin{tabular}{lll}
\hline Groups & N & Significance level \\
\hline $\begin{array}{l}\text { Difference between recall scores among extraverts } \\
\text { and introverts in the various auditory simulations }\end{array}$ & 121 & .825 \\
$\begin{array}{l}\text { Difference between recall scores among extraverts } \\
\text { and introverts in silence }\end{array}$ & 40 & .556 \\
\hline
\end{tabular}

DISCUSSION

This study dealt with the question as to if varying auditory environments affect prose retention. Referring to the reported results, the means of performing in pop music and classical music groups are greater than the means of white noise and silence groups, which does suggest better performance in the first two groups. But, according to the nonparametric tests report, the difference in performance isn't significant. Due to this, the hypothesis is rejected as there is no significant difference between the recall across the different auditory simulation groups. With this, we can assume these auditory simulations don't necessarily hinder the process of memory encoding and recall as all of them performed more or less with the same accuracy and efficiency but at the same time it doesn't significantly aid the process and reap better performance than the traditionally preferred silent environment. This is unlike many other studies that suggested that it was a factor that either degraded or improved performance (Sachs \& Carden, 2012; Taylor \& Rowe, 2012; Musliu et al., 2017; Smith 1985; Bird, 2017). Likewise, the extraversion and introversion factor didn't have any significant difference in performance quality irrespective of the presence or absence of auditory simulations. This was again unlike previous findings (Furnham \& Bradley, 1997; McDonald, 2013; Furnham \&Strbac, 2002). Although, if the means of the performance between introverts and extraverts in the presence of auditory simulation is compared, extraverts did slightly better than introverts. The study had an initial pre-test of attention as well as it was suggested to be a contributing factor during the process of review of literature, however, as the population was college students a general aboveaverage attention was seen and hence excluded from the final proceedings. An interesting observation during the analysis processes was the performance of students majoring in music. The sample had 43 students who were majoring in western classical music groups and regardless of the group they were in they performed significantly better than the samples average performance. This finding is in agreement with research done comparing working memory among musicians which suggested better performance than non-musicians (Gold et al, 2013; Saarikivi et al., 2019; Talamini et al., 2016, 2017).

\section{LIMITATION}

As the population were college students as the general performance quality was above average across the different groups hence the room for aid was relatively small. The 
population consisted of students from over 10 different courses from undergraduate and postgraduate level, though it made the sample diverse the use of prose retention for them all may not have been relevant as it students from humanities and social sciences field found it engaging but not so much for students from life sciences, commerce, and such fields. To make this more relevant for students from different fields, different memory tests could be implemented such as the reading span task created by Daneman and Carpenter, 1980; Or, memory tasks pertaining to the academic requirements of specific subjects (Mathy \& Chekaf, 2018) and (Conway \& Kane, 2005). A study conducted by Etaugh \& Ptasnik (1982) suggests students who frequently listen to music while engaging in cognitive tasks do better than those who don't do so. As the screening of this factor wasn't done it may have been an influencing variable or even a factor that could be studied and compared against each other. Cultural difference may have been also an influencing factor as western classical music is something very unfamiliar for most Indian students and also because classical music as a genre isn't enjoyed by the youth in India as much even if it is Indian classical. In addition to it from participant feedback and reaction it was observed that students in the classical music group tended to lose interest and finish the task in a hurry as compared to the ones who enjoyed classical music. The factor of the genre itself may have influenced the results as the preferred genre would keep the participants more engaged hence if the genre is one that the subject prefers but the auditory stimuli is a piece in the genre which isn't well known may reap better results. This could be done by perhaps having a pre-test questionnaire enquiring about their preferred genre of music, while in the case of white noise the same cannot be applied. As a conclusion, this study has found different auditory environmental simulation to have no negative or significantly positive impact on prose retention. The factor of contextdependent memory may also have played a role as encoding and recall wasn't done in the same context for all the groups except silence which was the control groups there are a few works which suggest that context is an influencing factor in performance (Smith, 2000; Grant et al, 1998).

\section{CONCLUSION}

Different auditory simulations have no negative or significant positive effect on performance in working memory tasks and personality types do not influence this phenomenon. However, it could be studied further by exploring the topic in-depth in a specific preferred genre with a relatively specific population and with memory tests of relevance for that population.

\section{REFERENCES}

Ackerman, P. L., \& Heggestad, E. D. (1997). Intelligence, personality, and interests: Evidence for overlapping traits. Psychological Bulletin, 121(2), 219-245. doi: 10.1037/0033-2909.121.2.219

Adam, G. (2011). The relationship between attention and working memory. 5. https://doi.org/10.3389/conf.fnhum.2011.207.00576

Allampati, S., Duarte-Rojo, A., Thacker, L. R., Patidar, K. R., White, M. B., Klair, J. S., ... Bajaj, J. S. (2016). Diagnosis of Minimal Hepatic Encephalopathy Using Stroop EncephalApp: A Multicenter US-Based, Norm-Based Study. American Journal of Gastroenterology, 111(1), 78-86. https://doi.org/10.1038/ajg.2015.377

Beethoven, L. V. (1844). Violin Concerto in D major, Op 61.

Bird, J. (2017). Listen Up! The Impact of Music on Students 'Reading Comprehension.

Bugter, D., \& Carden, R. (2012). The effect of music genre on a memory task. 
Campbell, J. B., \& Hawley, C. W. (1982). Study habits and Eysencks theory of extraversion-introversion. Journal of Research in Personality, 16(2), 139-146. doi: 10.1016/0092-6566(82)90070-8

Conway, A. R. A., Kane, M. J., Bunting, M. F., Hambrick, D. Z., Wilhelm, O., \& Engle, R. W. (2005). Working memory span tasks: A methodological review and user's guide. Psychonomic Bulletin \& Review, 12(5), 769-786. https://doi.org/10.3758/bf03196772

Cornoldi, C., \& Giofrè, D. (2014). The Crucial Role of Working Memory in Intellectual Functioning. 19(4), 260-268. https://doi.org/10.1027/1016-9040/a000183

David, N., Varughese, E., \& George, R. (2019). Effects of Music on the Psychological Wellbeing of Emerging Adults.

Deigård, D. (2012). The Effect of Acute Background Noise on Recognition Tasks. https://doi.org/10.1037/e529952013-001

Essel, G., \& Owusu, P. (2017). Causes of students' stress, its effects on their academic success, and stress management by students.

Etaugh, C., \& Ptasnik, P. (1982). Effects of Studying to Music and Post-Study Relaxation on Reading Comprehension. Perceptual and Motor Skills, 55(1), 141-142. doi: 10.2466/pms.1982.55.1.141

Fougnie, D. (2008). The Relationship between Attention and Working Memory.

Furnham, A., \& Bradley, A. (1997). Music while you work: the differential distraction of background music on the cognitive test performance of introverts and extraverts. 11(5), 445-455. https://doi.org/10.1002/(sici)1099-0720(199710)11:5

Furnham, A., \& Strbac, L. (2002). Music is as distracting as noise: the differential distraction of background music and noise on the cognitive test performance of introverts and extraverts. 45(3), 203-217. https://doi.org/10.1080/00140130210121932

Gold, B. P., Frank, M. J., Bogert, B., \& Brattico, E. (2013). Pleasurable music affects reinforcement learning according to the listener. 4. https://doi.org/10.3389/fpsyg.2013.00541

Grant, H. M., Bredahl, L. C., Clay, J., Ferrie, J., Groves, J. E., McDorman, T. A., \& Dark, V. J. (1998). Context-dependent memory for meaningful material: information for students. 12(6), 617-623. https://doi.org/10.1002/(sici)1099-0720(1998120)12:6.

Gray, J. R., \& Braver, T. S. (2002). Personality predicts working-memory-related activation in the caudal anterior cingulate cortex. Cognitive, Affective, \& Behavioral Neuroscience, 2(1), 64-75. doi: 10.3758/cabn.2.1.64

Hetland, L. (2000). Listening to Music Enhances Spatial-Temporal Reasoning: Evidence for the "Mozart Effect." 34(3/4), 105. https://doi.org/10.2307/3333640

Holmes, J., Dunning, D. L., \& Gathercole, S. E. (2010). Poor working memory: Impact and interventions. https://doi.org/https://doi.org/10.1016/B978-0-12-374748-8.00001-9

Hubbard, K. K., \& Blyler, D. (2016). Improving Academic Performance and Working Memory in Health Science Graduate Students Using Progressive Muscle Relaxation Training. 70(6), 7006230010p1. https://doi.org/10.5014/ajot.2016.020644

Jarrold, C. J. N. T., \& Towse, J. N. (2006). INDIVIDUAL DIFFERENCES IN WORKING MEMORY. https://doi.org/https://doi.org/10.1016/j.neuroscience.2005.07.002

Jensen, A. R. (1989). The relationship between learning and intelligence. 1(1), 37-62. https://doi.org/10.1016/1041-6080(89)90009-5

Keith J. Holyoak, \& Robert G. Morrison. (2005). The Cambridge Handbook of Thinking and Reasoning. Cambridge University Press.

Langan, K., \& Sachs, D. E. (2013). Opening Pandora's Stream: Piping Music into the Information Literacy Classroom. 
Lehmann, J. A. M., \& Seufert, T. (2017). The Influence of Background Music on Learning in the Light of Different Theoretical Perspectives and the Role of Working Memory Capacity. 8. https://doi.org/10.3389/fpsyg.2017.01902

Leon, B. (2009). Sunrise.Long, N. M., Kuhl, B. A., \& Chun, M. M. (2018). Memory and Attention. https://doi.org/10.1002/9781119170174.epcn109

Lukasik, K. M., Waris, O., Soveri, A., Lehtonen, M., \& Laine, M. (2019). The Relationship of Anxiety and Stress with Working Memory Performance in a Large Non-depressed Sample. 10. https://doi.org/10.3389/fpsyg.2019.00004

Malmberg, K. J., Raaijmakers, J. G. W., \& Shiffrin, R. M. (2019). 50 years of research sparked by Atkinson and Shiffrin (1968). Memory \& Cognition, 47(4), 561-574. https://doi.org/10.3758/s13421-019-00896-7

Martin, R. C., Wogalter, M. S., \& Forlano, J. G. (1988). Reading comprehension in the presence of unattended speech and music. 27(4), 382-398. https://doi.org/10.1016/0749-596x(88)90063-0

Mathy, F., Chekaf, M., \& Cowan, N. (2018). Simple and Complex Working Memory Tasks Allow Similar Benefits of Information Compression. 1(1). https://doi.org/10.5334/joc.31

Mcdonald, J. (2013). The Effect of Music Preference on Complex Task Performance.

Mensink, M. C., \& Dodge, L. (2014). Music and Memory: Effects of Listening to music while studying in college students.

Milton J. Dehn. (2011). Working Memory and Academic Learning. John Wiley \& Sons.

Musliu, A., Berisha, B., Latifi, D., \& Peci, D. (2017). The Impact of Music in Memory. https://doi.org/10.26417/ejser.v10i2.p222-227

Nadler, R. T., Rabi, R., \& Minda, J. P. (2010). Better Mood and Better Performance. 21(12), 1770-1776. https://doi.org/10.1177/0956797610387441

Noah B. Johansen. (2008). New Research on Short-term Memory. Nova Science Pub Incorporated.

Personality. (n.d.). Retrieved from https://www.apa.org/topics/personality/

Porcelli, A. J., Cruz, D., Wenberg, K., Patterson, M. D., Biswal, B. B., \& Rypma, B. (2008). The effects of acute stress on human prefrontal working memory systems. 95(3), 282-289. https://doi.org/10.1016/j.physbeh.2008.04.027

Rammstedt, B., Lechner, C., \& Danner, D. (2018). Relationships between Personality and Cognitive Ability: A Facet-Level Analysis. Journal of Intelligence, 6(2), 28. doi: 10.3390/jintelligence6020028

Renteria, S., Molina, G., Sainz, E., \& Serrano, L. (2014). BINAURAL AUDIO RELAXATION TECHNIQUES FOR PEOPLE WITH ANXIETY AND STRESS.

Sänger, J., Bechtold, L., Schoofs, D., Blaszkewicz, M., \& Wascher, E. (2014). The influence of acute stress on attention mechanisms and its electrophysiological correlates. 8 . https://doi.org/10.3389/fnbeh.2014.00353

Sakuraba, H. (2012). Do Simultaneously presented Visual and Auditory stimuli attract our attention? effects of divided attention on memory.

Salamé, P., \& Baddeley, A. (1989). Effects of Background Music on Phonological ShortTerm Memory. 41(1), 107-122. https://doi.org/10.1080/14640748908402355

Sarter, M., \& Lustig, C. (2009). Attention and learning and memory.

Smith, S. M. (1985). Background Music and Context-Dependent Memory. 98(4), 591. https://doi.org/10.2307/1422512

Smith, S. M., \& Vela, E. (2000). Environmental context-dependent memory: A review and meta-analysis. https://doi.org/https://doi.org/10.3758/BF03196157 
Stevens, F. L., Hurley, R. A., \& Taber, K. H. (2011). Anterior Cingulate Cortex: Unique Role in Cognition and Emotion. The Journal of Neuropsychiatry and Clinical Neurosciences, 23(2), 121-125. doi: 10.1176/jnp.23.2. jnp121

Söderlund, G. B., Sikström, S., Loftesnes, J. M., \& Sonuga-Barke, E. J. (2010). The effects of background white noise on memory performance in inattentive school children. 6(1), 55. https://doi.org/10.1186/1744-9081-6-55

Sutin, A. R., Stephan, Y., Luchetti, M., \& Terracciano, A. (2019). Five-factor model personality traits and cognitive function in five domains in older adulthood. BMC Geriatrics, 19(1). doi: 10.1186/s12877-019-1362-1

Taylor, J. M., \& J. Rowe, B. J. (2012). The "Mozart Effect" and the Mathematical Connection.

Thompson, W. F., Schellenberg, E. G., \& Letnic, A. K. (2011). Fast and loud background music disrupts reading comprehension. 40(6), 700-708. https://doi.org/10.1177/0305735611400173

Tiu, K. (2013). The Effect of Background Music to College Students' Academic Performance.

WJ, C., Hamid, A. A., \& JM, A. (2018). Working Memory From the Psychological and Neurosciences Perspectives: A Review. https://doi.org/10.3389/fpsyg.2018.00401

Zeidner, M., \& Matthews, G. (2000). Intelligence and Personality. Handbook of Intelligence, 581-610. doi: 10.1017/cbo9780511807947.027

http://play.google.com/store/apps/details?id=com.studionmd. whitenoise

http://toefl.uobabylon.edu.iq/papers/ibt_2015_1821899.pdf

\section{Acknowledgement}

We would like to thank CHRIST (Deemed to be University) for permitting us to conduct experiments on campus, as well as the participants for sharing their time and energy.

\section{Conflict of Interest}

The author declared no conflict of interest.

How to cite this article: David N., Muzeyi K. \& Prasadam S.E. (2021). Effects of Auditory Simulation and Personality Types on Working Memory. International Journal of Indian Psychology, 9(1), 1386-1396. DIP:18.01.144/20210901, DOI:10.25215/0901.144 